
\title{
$\begin{array}{ll}\text { Research Square } & \text { Preprints are preliminary reports that have not undergone peer review. } \\ \text { They should not be considered conclusive, used to inform clinical practice, } \\ \text { or referenced by the media as validated information. }\end{array}$
}

\section{Community Socioeconomic Disadvantage Drives Type of 30-Day Medical-Surgical Revisits Among Patients with Serious Mental Illness}

\author{
Hayley Drew Germack ( $\nabla$ hdg8@pitt.edu ) \\ University of Pittsburgh School of Nursing https://orcid.org/0000-0002-0035-6301 \\ Mandy Cooper \\ University of Pittsburgh School of Nursing \\ Krista Koller \\ University of Pittsburgh College of General Studies \\ Khadejah Mahmoud \\ University of Pittsburgh Graduate School of Public Health \\ Heather Vincent \\ University of Pittsburgh School of Nursing \\ Grant R. Martsolf \\ University of Pittsburgh School of Nursing
}

\section{Research article}

Keywords: revisits, readmissions, observation stays, socioeconomic disadvantage, mental illness

Posted Date: October 19th, 2020

DOI: https://doi.org/10.21203/rs.3.rs-92546/v1

License: (c) (i) This work is licensed under a Creative Commons Attribution 4.0 International License. Read Full License

Version of Record: A version of this preprint was published at BMC Health Services Research on July 5th, 2021. See the published version at https://doi.org/10.1186/s12913-021-06605-y. 


\section{Abstract}

Background: Patients with serious mental illness (SMI) are vulnerable to medical-surgical readmissions and emergency department visits. Community socioeconomic disadvantage has been associated with readmission risk in the general population, but its impact on other types of revisits (emergency department visits and observation stays), particularly in patients with SMI, is unknown.

Methods: We used Agency for Healthcare Research and Quality Healthcare Cost and Utilization Project discharge abstracts for 1,914,619 patients with SMI discharged after medical-surgical admissions in Florida and New York between 2012 and 2015 and their revisits to the hospital within 30 days of discharge. We linked this data to the Area Deprivation Index for the communities that patients returned to.

Results: Patients with SMI returning to the most disadvantaged communities had greater adjusted 30-day revisit rates than patients from less disadvantaged communities. Among those that experienced a revisit, patients returning the most disadvantaged communities had 7.3\% greater 30-day observation stay revisits.

Conclusion: These results suggest that additional investments are needed to ensure that patients with SMI returning the most socioeconomically disadvantaged communities are receiving appropriate post-discharge care.

\section{Background}

People with serious mental illness (SMl; i.e., schizophrenia, major depressive disorder, and bipolar disorder) are at increased risk of morbidity and mortality compared to the general population $(1,2)$. In fact, SMI is associated with nearly 8 years of reduced life expectancy (2), attributable to the high prevalence of diabetes, cardiovascular disease and hypertension in this population $(3,4)$. While researchers often focus on psychiatric hospitalizations for people with SMI, it is critical to attend to their higher than average medical hospitalizations. People with SMI have higher rates of inpatient hospitalization $(5,6)$ and emergency department (ED) visits (7)-contributing to their four times greater healthcare expenditures (8). They are particularly vulnerable to revisits (i.e. unplanned returns to the hospital within 30 days of discharge including ED visits and readmissions [unplanned admissions to medical-surgical units]) after medical-surgical hospitalizations given pronounced barriers in engaging in positive health behaviors $(9,10)$.

The empirical literature has documented associations between readmissions among adults with SMI and the communities that they are discharged to. One study identified a higher likelihood of 1-year psychiatric readmission among Hispanic patients, patients with at least one prior hospitalization, patients discharged to a location near a Narcotics Anonymous meeting place, and residing in an area with low educational attainment (11). Another study found that community residential mobility (i.e. a combination of the percentage of residents living in a different house in the past year and the percentage of non-owner occupied housing) was significantly associated with fewer mental health visits even after controlling for other community-and individual-level factors among people with SMI and comorbid medical illness (12). Many studies have established that people who live in socioeconomically disadvantaged communities (i.e. communities challenged by low income, limited education, and substandard living conditions) (13) have worse mental and physical health outcomes than people living in more socioeconomically advantaged communities $(14,15)$. People with SMI often live in disadvantaged communities $(16)$. However, previous research has not extensively explored the community context which this population returns to after discharge from medical-surgical hospitalizations $(17,18)$. Community-level factors can influence health outcomes independently of commonly measured individual-level factors, through pathways such as exposure to chronic stress, lack of access to proper follow up care (e.g. no local primary care availability), and lack of healthy food availability (e.g. no stores that 
offer health food in the communities), each of which may exacerbate existing conditions and increase the likelihood of readmission $(19,20)$.

Research investigating the association between community socioeconomic disadvantage and readmissions has increased in recent years, but these studies largely ignore the other types of acute, unscheduled post-discharge revisits $(13,21)$. Patients can also return to the emergency department (ED) or they may be admitted on observation units, without requiring a formal readmission (i.e. an inpatient stay) (22). Observation stays are replacing some readmissions, making it important to capture observation stays as a type of revisit (23). There are significant gaps in our understanding of how community socioeconomic disadvantage impacts revisits to the emergency department and observation stays, particularly among people with SMI, who are largely impacted by the community in which they live. Understanding the relationship between community socioeconomic disadvantage and different types of medicalsurgical revisits (ED visits, observation stays, and readmissions) in this population is necessary as researchers pay greater attention to the relationship between social determinants of health and health outcomes including unscheduled post-discharge care.

Given what is known about the complex mechanisms that drive revisits, examining the association between community socioeconomic disadvantage and medical-surgical revisits among patients with comorbid SMI is important. Understanding the community socioeconomic context which people return to is critical because postdischarge follow-up occurs within a geographic area (e.g. county, community) and community factors summarized by community socioeconomic disadvantage are associated with greater risk of 30-day readmission in the general population (21). This study used four years (2012-2015) of discharge data from two large states (Florida and New York) to examine whether community socioeconomic disadvantage was associated with 30-day medical-surgical revisits in patients with SMI after adjusting for patient and hospital-level characteristics.

\section{Methods}

\section{Database and Study Population}

We examined acute care utilization for adults (age $\geq 18$ years) using Healthcare Cost and Utilization Project (HCUP) 2012-2015 (quarter 3) discharge data from Florida and New York from the State Inpatient Database (SID), State Emergency Department Database (SEDD), and State Ambulatory Surgery and Services Database (SASD) from the Agency for Healthcare Research and Quality (AHRQ). Florida and New York comprise $12 \%$ of the US population and their discharge data had encrypted patient identification numbers that permitted linkage across facilities and hospitals. The years 2012-2015 were selected because they occurred after the Hospital Readmission Reduction Program took effect and before ICD-10 changes in coding were implemented. The SID, SEDD, and SASD are all-payer databases, containing discharges from nonfederal, non-psychiatric community hospitals and emergency departments. They contain more than 100 clinical and nonclinical variables including principal and secondary diagnoses and procedures, admission and discharge status, patient demographics, and length of stay $($ LOS $)(24,25)$.

We combined patient-level data from the 2012-2015 SID, SEDD, and SASD with hospital-level data from the 2015 American Hospital Association (AHA) Annual Survey, community-level data from the 2015 Area Health Resources Files (AHRF) and with ZIP-level data for 2015 from the University of Wisconsin Neighborhood Atlas ${ }^{\circledR}$ Area Deprivation Index (ADI) (26).

We included all non-psychiatric medical-surgical admissions. Index admissions for patients aged 18 years and older were considered if they occurred at nonfederal general medical-surgical hospitals. Using AHRQ Clinical Classification Software (CCS) codes, all discharge records for patients with comorbid diagnoses of SMI were identified 
(Supplementary File 1). Patients were excluded from the cohort if they: 1) did not survive to discharge; 2) had an admission with a primary diagnosis of SMl; 3) had an index length of stay of less than or equal to one day; 4) discharged against medical advice; and 5) were admitted for a diagnosis category or a procedure considered planned (i.e. primary diagnosis of cancer or procedures including obstetrical delivery, transplant surgery, maintenance chemotherapy, rehabilitation; ICD9 and AHRQ CCS categories used to identify planned admissions in the Supplementary File 1) (27).

\section{Measures}

\section{Community Socioeconomic Disadvantage}

2015 data from the University of Wisconsin Neighborhood Atlas ${ }^{\circledR}$ ADI (26) were used to characterize patients' community socioeconomic disadvantage. The ADI allows for rankings of neighborhoods by socioeconomic status disadvantage in a region of interest (e.g. at the state or national level). It uses American Community Survey (ACS) Five Year Estimates in its construction. The 2015 ADI used the ACS data for 2015, which is a 5-year average of ACS data obtained from 2011-2015. It includes factors from the theoretical domains of income, education, employment, and housing quality. In the present study, ADIs were aggregated to the ZIP-level for communities in Florida and New York. Communities were compared independently for Florida and New York-the 50\% least disadvantaged communities were grouped together; the $45 \%$ middle disadvantaged communities were grouped together; and the $5 \%$ most disadvantaged communities were grouped together.

\section{Revisit Types}

The revisit was defined as the first revisit for a physical health condition within 30 days of discharge. For the purpose of this study, revisit types include ED visits, observational stays and readmissions. The primary outcomes of interest were three types of medical-surgical revisit: 1) having an ED visit within 30-days of discharge; 2) having an observation stay within 30 days of discharge; and 3) having a readmission within 30 days of discharge. An additional outcome included having any type of revisit within 30 days of discharge (i.e. ED visit or observation stay or readmission). ED visits, observation stays, and readmissions were identified using the HCUP supplemental variables for revisit analysis, which provide a unique visit link to allow for each patient to be tracked at subsequent inpatient visits across time and institutions (28).

\section{Statistical Analysis}

Individual patient-level demographic (i.e. age, sex, primary payer [Medicare, Medicaid, private, self-pay, no charge, or other]) and clinical characteristics (length of stay of the index admission, admission type [emergency, urgent, elective, or trauma center] an indicator for if they had a surgical procedure, Elixhauser comorbidity readmission risk score, and DRG of the index admission), hospital-level characteristics (teaching status of the hospital [member of Council of Accredited Teaching Hospitals], total number of hospital beds, technology status of the hospital [i.e. capable of performing heart transplant or adult interventional cardiac catheterization], the hospital's nurse-to-bed ratio, and the ownership status of the hospital [i.e. non-federal government, private for profit, or private not-for-profit]), and community characteristics (rurality, health care provider supply [ratio of primary care physicians to county population and ratio of nurse practitioners to county population]) were compared by community socioeconomic disadvantage category (least 50\% disadvantaged; middle 45\% disadvantaged; and 5\% most disadvantaged) using chi-squared tests for categorical variables and analysis of variance for continuous variables. 
Multivariate logistic regression models with state and year fixed effects were used to examine the relationship between a patient's community socioeconomic disadvantage category and revisits (any revisit and by revisit type) after adjusting for patient, hospital, and community-level factors. Among patients who experienced a revisit, a second set of logistic regression models were used to examine the relationship between community socioeconomic disadvantage and revisit type after adjusting for patient, hospital, and community-level factors. Post-estimation commands were used to estimate the adjusted revisit rates of each type of revisit by community socioeconomic disadvantage. Statistical analyses were performed using STATA statistical software, version 16.1 (StataCorp, College Station, TX). For all analyses, $p$ values of $<0.05$ were considered statistically significant.

\section{Results}

As presented in Table 1, patients' demographic and clinical characteristics differed significantly between patients living in communities characterized by different levels of socioeconomic disadvantage. Patients whose primary residence was in the most disadvantaged communities were on average, nearly 5 years younger than those from the most advantaged communities (53.7 years vs. 58.5 years, $p<0.001$ ). A greater proportion of patients from the most disadvantaged communities were female (52.4\% vs. 50.3\%: $p<0.001)$. There was also a significant difference in the distribution of patients based on primary payer status-among patients from the most disadvantaged communities, Medicaid paid $33.9 \%$ of admissions compared to $16.4 \%$ from the least disadvantaged communities $(p<0.001)$. 
Table 1

Patient Demographic and Clinical Characteristics, by Community Socioeconomic Disadvantage; Florida and New York, 2012-2015

\begin{tabular}{|c|c|c|c|c|c|}
\hline & $\begin{array}{l}\text { All } \\
\text { patients }\end{array}$ & $\begin{array}{l}\text { Least } \\
\text { Disadvantaged }\end{array}$ & $\begin{array}{l}\text { Middle } 45 \% \\
\text { Disadvantaged }\end{array}$ & $\begin{array}{l}\text { Top 5\% } \\
\text { Disadvantaged }\end{array}$ & $\begin{array}{l}\mathrm{p}- \\
\text { value }\end{array}$ \\
\hline Demographics & $\begin{array}{l}N= \\
1,915,039\end{array}$ & $n=958,196$ & $n=865,655$ & $n=91,188$ & \\
\hline Age (mean, SD) & $57.7,17.1$ & $58.5,17.5$ & $57.2,16.8$ & $53.7,16.1$ & $\begin{array}{l}< \\
0.001\end{array}$ \\
\hline Age $(\mathrm{N}, \%)$ & & & & & $\begin{array}{l}<.001 \\
0.001\end{array}$ \\
\hline $18-44$ & $\begin{array}{l}421,194 \\
22.0 \%\end{array}$ & $203,676,21.3 \%$ & $192,651,22.3 \%$ & $24,867,27.3 \%$ & \\
\hline $45-64$ & $\begin{array}{l}802,649 \\
41.9 \%\end{array}$ & $385,388,40.2 \%$ & $373,659,43.1 \%$ & $43,602,47.8 \%$ & \\
\hline $65+$ & $\begin{array}{l}691,196 \\
36.1 \%\end{array}$ & $369,132,38.5 \%$ & $299,345,34.6 \%$ & $22,719,24.9 \%$ & \\
\hline Female $(\mathrm{N}, \%)$ & $\begin{array}{l}987,148 \\
51.6 \%\end{array}$ & $481,688,50.3 \%$ & $457,694,52.9 \%$ & $47,766,52.4 \%$ & $<0.001$ \\
\hline Primary Payer (N, \%) & & & & & $\begin{array}{l}< \\
0.001\end{array}$ \\
\hline Medicare & $\begin{array}{l}867,429 \\
45.3 \%\end{array}$ & $430,697,45.0 \%$ & $401,793,46.4 \%$ & $34,939,38.3 \%$ & \\
\hline Medicaid & $\begin{array}{l}341,919 \\
17.9 \%\end{array}$ & $156,762,16.4 \%$ & $154,258,17.8 \%$ & $30,899,33.9 \%$ & \\
\hline Private & $\begin{array}{l}460,920 \\
24.1 \%\end{array}$ & $270,892,28.3 \%$ & $177,315,20.5 \%$ & $12,713,13.9 \%$ & \\
\hline Self-Pay & $\begin{array}{l}140,339 \\
7.3 \%\end{array}$ & $56,227,5.9 \%$ & $76,614,8.9 \%$ & $7,498,8.2 \%$ & \\
\hline No Charge & $\begin{array}{l}30,713 \\
1.6 \%\end{array}$ & $10,220,1.1 \%$ & $18,750,2.2 \%$ & $1,743,1.9 \%$ & \\
\hline Other & $\begin{array}{l}73,719 \\
3.9 \%\end{array}$ & $33,398,3.5 \%$ & $36,925,4.3 \%$ & $3,396,3.7 \%$ & \\
\hline \multicolumn{6}{|l|}{ Clinical Characteristics } \\
\hline Length of Stay, days (mean, SD) & $4.8,5.1$ & $4.8,5.0$ & $4.7,5.0$ & $5.2,6.3$ & $\begin{array}{l}< \\
0.001\end{array}$ \\
\hline Admission Type (N, \%) & & & & & $\begin{array}{l}< \\
0.001\end{array}$ \\
\hline Emergency & $\begin{array}{l}1,439,740 \\
75.2 \%\end{array}$ & $720,846,75.3 \%$ & $646,159,74.7 \%$ & $72,735,79.8 \%$ & \\
\hline Urgent & $\begin{array}{l}152,640 \\
8.0 \%\end{array}$ & $68,358,7.1 \%$ & $79,382,9.2 \%$ & $4,900,5.4 \%$ & \\
\hline
\end{tabular}

Note: SD = Standard Deviation 


\begin{tabular}{|llllll|}
\hline & $\begin{array}{l}\text { All } \\
\text { patients }\end{array}$ & $\begin{array}{l}\text { Least } \\
\text { Disadvantaged }\end{array}$ & $\begin{array}{l}\text { Middle 45\% } \\
\text { Disadvantaged }\end{array}$ & $\begin{array}{l}\text { Top 5\% } \\
\text { Disadvantaged }\end{array}$ & $\begin{array}{l}\text { p- } \\
\text { value }\end{array}$ \\
\hline Elective & $\begin{array}{l}311,958, \\
16.3 \%\end{array}$ & $164,786,17.2 \%$ & $134,218,15.5 \%$ & $12,954,14.21$ \\
\hline Trauma Center & $\begin{array}{l}10,281, \\
0.5 \%\end{array}$ & $3,954,0.4 \%$ & $5,757,0.7 \%$ & $570,0.6 \%$ & \\
\hline Surgical admission (N, \%) & $\begin{array}{l}958,196, \\
50 \%\end{array}$ & 274,237, & $233,221,26.9 \%$ & $21,163,23.21 \%$ & $<$ \\
\hline $\begin{array}{l}\text { Elixhauser comorbidity } \\
\text { readmission risk score (mean, SD) }\end{array}$ & $12.5,11.7$ & $11.9,11.5$ & $13.1,11.9$ & $14.5,12.5$ & $<$ \\
\hline Note: SD = Standard Deviation & & & & & \\
\hline
\end{tabular}

There were also significant differences in patients' clinical characteristics based on their community's socioeconomic disadvantage. Compared to patients from the middle and least disadvantaged communities, patients from the most disadvantaged communities had longer lengths of stay (5.2 days vs. 4.7 and 5.8; $p<0.001$ ), were more likely to be admitted for emergency reasons (as opposed to elective) (79.8\% vs. $74.7 \%$, and $75.3 \% ; p<0.001$ ), and had a higher Elixhauser comorbidity readmission risk score (14.5 vs 13.1, and 11.9; $\mathrm{p}<0.001)$. Supplementary File 2 displays that across all three categories of community disadvantage, patients had similar reasons for admission-the most common being cardiac (17.9\%), followed by nervous system (7.2\%), COPD/asthma (7.0\%), alcohol/drug (5.7\%), and renal failure (4.5\%).

As presented in Table 2, hospital characteristics differed significantly between patients living in communities characterized by different levels of socioeconomic disadvantage. Greater proportions of patients from the least and most disadvantaged communities received care in teaching hospitals $(29.7 \%$ and $24.9 \%$ vs $17.5 \% ; p<0.001)$. A greater proportion of patients from the most disadvantaged communities received care hospitals with a high technology status $(78.4 \%$ vs. $65.4 \%$ and $67.5 \%, p<.001)$. Furthermore, a greater proportion of patients from the least and most disadvantaged communities received care in private, not-for profit hospitals $(74.6 \%$ and $71.2 \%$ vs. $59.2 \%$; $p$ $<0.001$ ). 
Table 2

Hospital Characteristics, by Community Socioeconomic Disadvantage; Florida and New York, 2012-2015

\begin{tabular}{|c|c|c|c|c|c|}
\hline Characteristic & All patients & $\begin{array}{l}\text { Least } \\
\text { Disadvantaged }\end{array}$ & $\begin{array}{l}\text { Middle 45\% } \\
\text { Disadvantaged }\end{array}$ & $\begin{array}{l}\text { Top 5\% } \\
\text { Disadvantaged }\end{array}$ & $\begin{array}{l}\mathrm{p}- \\
\text { value }\end{array}$ \\
\hline & $\begin{array}{l}N= \\
1,915,039\end{array}$ & $n=958,196$ & $n=865,655$ & $n=91,188$ & \\
\hline Teaching Hospital (N, \%) & $\begin{array}{l}458,359 \\
23.9 \%\end{array}$ & $284,508,29.7 \%$ & $151,149,17.5 \%$ & $22,702,24.9 \%$ & $<.001$ \\
\hline Bed Size (mean, SD) & $551.1,501.0$ & $557.1,484.3$ & $529.0,518.7$ & $697.5,475.4$ & $<001$ \\
\hline \multicolumn{6}{|l|}{ Bed Size, category (N, \%) } \\
\hline $6-24$ & $2,322,0.1 \%$ & $569,0.1 \%$ & $1,694,0.2 \%$ & $59,0.1 \%$ & $<.001$ \\
\hline $25-49$ & $8,320,0.4 \%$ & $1,681,0.2 \%$ & $5,857,0.7 \%$ & $782,0.9 \%$ & \\
\hline $50-99$ & $\begin{array}{l}79,460 \\
4.2 \%\end{array}$ & $36,083,3.8 \%$ & $40,373,4.7 \%$ & $3,004,3.3 \%$ & \\
\hline $100-199$ & $\begin{array}{l}267,292 \\
14.0 \%\end{array}$ & $118,027,12.3 \%$ & $144,324,16.7 \%$ & $4,941,5.4 \%$ & \\
\hline $200-299$ & $\begin{array}{l}346,423 \\
18.1 \%\end{array}$ & $159,656,16.7 \%$ & $177,074,20.5 \%$ & $9,693,10.6 \%$ & \\
\hline $300-399$ & $\begin{array}{l}252,688 \\
13.2 \%\end{array}$ & $148,950,15.5 \%$ & $97,913,11.3 \%$ & $5,825,6.4 \%$ & \\
\hline $400-499$ & $\begin{array}{l}219,120 \\
11.4 \%\end{array}$ & $90,412,9.4 \%$ & $114,630,13.2 \%$ & $14,078,15.4 \%$ & \\
\hline $500+$ & $\begin{array}{l}739,414 \\
38.6 \%\end{array}$ & $402,818,42.0 \%$ & $283,790,32.8 \%$ & $52,806,57.9 \%$ & \\
\hline $\begin{array}{l}\text { High technology status } \\
(\mathrm{N}, \%)\end{array}$ & $\begin{array}{l}1,284,471 \\
67.1 \%\end{array}$ & $646,806,67.5 \%$ & $566,200,65.4 \%$ & $71,465,78.4 \%$ & $<.001$ \\
\hline $\begin{array}{l}\text { Number of RNs per Bed } \\
\text { (mean, SD) }\end{array}$ & $1.5,0.6$ & $1.6,0.6$ & $1.4,0.6$ & $1.4,0.6$ & $<.001$ \\
\hline Ownership (N, \%) & & & & & $\begin{array}{l}< \\
0.001\end{array}$ \\
\hline $\begin{array}{l}\text { Nonfederal, government } \\
\text { run }\end{array}$ & $\begin{array}{l}228,417 \\
11.9 \%\end{array}$ & $118,441,12.4 \%$ & $96,935,11.2 \%$ & $13,041,14.3 \%$ & \\
\hline Private, not-for-profit & $\begin{array}{l}1,291,570 \\
67.4 \%\end{array}$ & $714,434,74.6 \%$ & $512,260,59.2 \%$ & $64,876,71.2 \%$ & \\
\hline Private, for-profit & $\begin{array}{l}395,052 \\
20.6 \%\end{array}$ & $125,321,13.1 \%$ & $256,460,29.63 \%$ & $13,271,14.6 \%$ & \\
\hline
\end{tabular}

As presented in Table 3, community characteristics differed substantially by community socioeconomic disadvantage. Compared to patients from the least disadvantaged communities, those from the most disadvantaged communities were more likely to be in rural counties (76\% vs $74.6 \% ; p<0.001)$. Additionally, they were from counties 
with fewer primary care physicians (251/10,000 county population vs. 299/10,000 county population; $p<0.001)$, and more nurse practitioners ( 69 per 10,000 county population vs. 56 per 10,000 county population; $p<0.001$ ).

Table 3

Community Characteristics, by Community Socioeconomic Disadvantage; Florida and New York, 2012-2015

\begin{tabular}{|c|c|c|c|c|c|}
\hline Characteristic & $\begin{array}{l}\text { All } \\
\text { patients }\end{array}$ & $\begin{array}{l}\text { Least } \\
\text { Disadvantaged }\end{array}$ & $\begin{array}{l}\text { Middle 45\% } \\
\text { Disadvantaged }\end{array}$ & $\begin{array}{l}\text { Top 5\% } \\
\text { Disadvantaged }\end{array}$ & $\begin{array}{l}\mathrm{p}- \\
\text { value }\end{array}$ \\
\hline & $\begin{array}{l}N= \\
1,915,039\end{array}$ & $n=958,196$ & $n=865,655$ & $n=91,188$ & $\begin{array}{l}< \\
0.001\end{array}$ \\
\hline Rural County (N, \%) & $\begin{array}{l}1,451,410 \\
(75.8)\end{array}$ & 714,750 (74.6) & $667,354(77.1)$ & $69,306(76)$ & $\begin{array}{l}< \\
0.001\end{array}$ \\
\hline $\begin{array}{l}\text { Ratio of Primary Care Physicians } \\
\text { per } 10,000 \text { Persons in County } \\
\text { (mean, SD) }\end{array}$ & 266 (178) & 299 (181.1) & $230(171.1)$ & 251 (108.6) & $\begin{array}{l}< \\
0.001\end{array}$ \\
\hline $\begin{array}{l}\text { Ratio of Nurse Practitioners per } \\
10,000 \text { Persons in County (mean, } \\
\text { SD) }\end{array}$ & $\begin{array}{l}59.1 \\
(32.3)\end{array}$ & $56.1(31.9)$ & $61.3(31.9)$ & $69.1(37.7)$ & $\begin{array}{l}< \\
0.001\end{array}$ \\
\hline
\end{tabular}

Figure 1 displays the post-estimation adjusted 30-day revisit rates by community socioeconomic disadvantage (full regression models shown in Supplementary File 3). The adjusted revisit rates were $30.33 \%$ among patients in the most disadvantaged communities, $25.06 \%$ in the middle $45 \%$ of disadvantaged communities, and $25.94 \%$ in the least disadvantaged communities. There were significant differences in the distribution of revisit type. The adjusted ED revisit rate was $10.44 \%(p<0.001)$ among patients in the most disadvantaged communities compared to $10.66 \%(p<$ 0.001 ) in the middle disadvantaged communities, and $9.23 \%$ in the least disadvantaged. The adjusted observation stay revisit rate was $10.58 \%(p<0.001)$ among patients from the most disadvantaged communities, $7.28 \%(p=0.042)$ in the middle disadvantaged communities and $10.58 \%$ in the most disadvantaged communities. The adjusted readmission revisit rate was $8.73 \%(p=0.037)$ among patients in the most disadvantaged communities compared to $8.68 \%(p<0.001)$ in the middle $45 \%$ and $8.53 \%$ in the least disadvantaged communities $(p<0.001)$.

Figure 2 displays the post-estimation adjusted 30-day revisit rates among individuals who experience a revisit, by community socioeconomic disadvantage. The adjusted ED revisit rate was $35.39 \%(p<0.001)$ among the most disadvantaged, $40.28 \%$ ( $<<0.001)$ among the middle $45 \%$, and $36.83 \%$ among the least disadvantaged. The adjusted observation stay revisit rate was $35.30 \%(p<0.001)$ among the most disadvantaged, $26.99 \%(p<0.001)$ among the middle $45 \%$, and $28.99 \%$ among the least disadvantaged. The adjusted readmission rate was $29.42 \%(p<0.001)$ among the most disadvantaged, $32.70 \%(p<0.001)$ among the middle deprived, and $34.07 \%$ among the least disadvantaged. Patients from the most disadvantaged communities experienced a $6.31 \%$ greater adjusted rate of observation stay revisits compared to patients from the least disadvantaged communities.

\section{Discussion}

In this cross-sectional, retrospective study of discharge data for patients with SMI from Florida and New York between 2012 and 2015, we showed that community socioeconomic disadvantage was significantly associated with revisits among patients with SMI even after adjusting for patient and hospital characteristics. This finding is consistent with other work supporting the impact of community socioeconomic disadvantage on health outcomes $(11,13,21)$. For example, Kind et al. found that residents of the most disadvantaged communities had higher rates of 30-day 
readmissions than residents of less disadvantaged communities (13). Hu et al. extended the study by finding that patients residing in the most disadvantaged communities had significantly higher 30-day readmission risk compared to those in less disadvantaged communities even after accounting for individual-level factors (i.e. age, sex, race, marital status, primary diagnosis at the time of discharge, and comorbidities) (21).

The findings we found about the significant relationship between community socioeconomic disadvantage and revisits were consistent across all types of revisits (ED visits, observation stays, and readmissions) within 30-days of discharge. Patients from the most disadvantaged communities had over $3 \%$ greater observation stay adjusted revisit rates than patients from the middle and least disadvantaged communities. Among the 497,243 patients who had a revisit over the time period, patients from the most disadvantaged communities had 30-day observation stay revisit rates 7.3 percentage points higher than the middle and least disadvantaged communities. They were less likely to experience a 30-day readmission or a 30-day ED visit. This could be explained as observation and ED visits are less costly to payers than inpatient admissions (29). This finding was consistent with one study using 2013 Medicare claims, which found that low-income Medicare beneficiaries are at greater risk of high use of observation care (30).

One other study using 2013 Medicare claims found that low-income Medicare beneficiaries are at greater risk of high use of observation care (30). Several factors could contribute to the higher adjusted observation stay revisits rates among patients from the most disadvantaged communities. First, prior work has demonstrated an association between poverty and high use of hospital services (31). Second, the hospitals to which they are being readmitted may be trying to reduce readmissions by intentionally placing these patients under observation instead of readmitting them $(32,33)$. Third, hospitals may be unintentionally admitting these patients as observation stays. Specifically, clinical practice patterns are changing so that patients admitted for acute reasons are admitted under observation or discharged from the ED instead of being admitted to inpatient units (34). Lastly, more patients from disadvantaged communities might be returning for lower-acuity conditions that can be treated under observation without a hospital admission. Prior studies have found that chronic disease burden and black race-both reflective of patients in more disadvantaged communities-predicted higher use of observation services (35). Patients in more disadvantaged communities likely have poorer access to primary care management and follow-up after their medical-surgical hospitalizations and need acute care services that do not necessitate a hospital readmission.

\section{Limitations}

The findings in this study are subject to limitations. First, the data used in this study are only from two states, so the findings reported here may not be generalizable to other communities or to other states. The ability to detect an effect

of community socioeconomic disadvantage and the relationship between disadvantage and different types of revisits may differ across study contexts (e.g. different states). Therefore, further research is needed that examines the relationship between community socioeconomic disadvantage and revisits nationally. Second, even though a wide range of variables were considered in the analyses based on the existing literature, we were not able to completely disaggregate the effects of patient and hospital level characteristics given their complex interplay. Third, we only had access to the five-digit ZIP codes of patients, so we were not able to use the more granular ADI ZIP +4 characteristics.

\section{Conclusion}

The results of this study strongly suggest that individuals with SMI from more disadvantaged communities have higher rates of 30-day revisits and specifically higher rates of 30-day observation stays. The ever-widening gap between advantaged and disadvantaged communities may exacerbate poor health outcomes. This poses questions about appropriate investments in disadvantaged communities to reduce disparities in health outcomes. Future work

Page $10 / 16$ 
should compare the impact of socioeconomic disadvantage on outcomes of patients with SMI to those without SMI.

Future work should also consider additional characteristics of the revisits, such as revisit diagnosis, which may help explain the differences in revisit type. Additionally, future work should investigate the effects of other community-level health investments such as availability of primary care clinics and federally qualified health centers on health outcomes like revisits.

\section{Abbreviations}

SMI - serious mental illness (i.e., schizophrenia, major depressive disorder, and bipolar disorder)

ED - emergency department

HCUP - Healthcare Cost and Utilization Project

SID - State Inpatient Database

SEDD - State Emergency Department Database

SASD - State Ambulatory Surgery and Services Database

LOS - length of stay

AHRQ - Agency for Healthcare Research and Quality

AHA - American Hospital Association

AHRF - Area Health Resources Files

ADI - University of Wisconsin Neighborhood Atlas ${ }^{\circledR}$ Area Deprivation Index

CCS - AHRQ Clinical Classification Software

ACS - American Community Survey

DRG - diagnosis-related group

\section{Declarations}

Ethics approval and consent to participate: Not applicable

Consent for publication: Not applicable

Availability of data and materials: Results generated or analyzed during this study are included in this published article and its supplementary information files. The raw data that supports the findings of this study, however, is available from the Agency for Healthcare Research and Quality's Healthcare Cost and Utilization Project (HCUP), but restrictions apply to the availability of this data under their Data Use Agreement. The data used for this study was used under a DUA with HCUP.

Competing interests: The authors declare that they have no competing interests 
Funding: Drs. Germack and Martsolf are supported by a grant from the University of Pittsburgh School of Nursing Center for Research and Evaluation and the University of Pittsburgh Central Research Development Fund. The content is solely the responsibility of the authors and does not necessarily represent the official views of these organizations.

Authors' contributions: All author listed on this manuscript have contributed extensively to the project to be included as authors. HG contributed to the conception of the study, the design of the work, the acquisition and analysis of the data, the interpretation of the data, and drafting the work. MC contributed to revising the manuscript. KK contributed to revising the manuscript. KM contributed to drafting and revising the work. HV contributed to revising the work. GM contributed to the conception of the study, interpretation of the data, and revising the work. All authors have approved the final manuscript.

Acknowledgements: Not applicable

\section{References}

1. Parks J, Svendsen D, Singer P. Morbidity and mortality in people with serious mental illness 2006 [updated Accessed September 29, 2017. . Available from:

https://www.nasmhpd.org/sites/default/files/Mortality\%20and\%20Morbidity\%20Final\%20Report\%208.18.08.pdf.

2. Druss BG, Zhao L, Von Esenwein S, Morrato EH, Marcus SC. Understanding excess mortality in persons with mental illness: 17-year follow up of a nationally representative US survey. Medical Care. 2011;49(6):599-604.

3. Janssen EM, McGinty EE, Azrin ST, Juliano-Bult D, Daumit GL. Review of the evidence: Prevalence of medical conditions in the United States population with serious mental illness. General Hospital Psychiatry.

2015;37(3):199-222.

4. Osborn DP, Wright CA, Levy G, King MB, Deo R, Nazareth I. Relative risk of diabetes, dyslipidaemia, hypertension and the metabolic syndrome in people with severe mental illnesses: Systematic review and metaanalysis. BMC Psychiatry. 2008;8(1):84.

5. Payne RA, Abel GA, Guthrie B, Mercer SW. The effect of physical multimorbidity, mental health conditions and socioeconomic deprivation on unplanned admissions to hospital: A retrospective cohort study. Canadian Medical Association Journal. 2013;185(5):E221-E8.

6. Li Y, Glance LG, Cai X, Mukamel DB. Mental illness and hospitalization for ambulatory care sensitive medical conditions. Medical Care. 2008;46(12):1249-56.

7. Shim RS, Druss BG, Zhang S, Kim G, Oderinde A, Shoyinka S, et al. Emergency department utilization among Medicaid beneficiaries with schizophrenia and diabetes: The consequences of increasing medical complexity. Schizophrenia Research. 2014;152(2-3):490-7.

8. Fitch K, Iwasaki K, Villa KF. Resource utilization and cost in a commercially insured population with schizophrenia. American Health \& Drug Benefits. 2014;7(1):18.

9. Germack HD, Noor EAM, Wang X, Hanrahan N. Association of comorbid serious mental illness diagnosis with 30day medical and surgical readmissions. JAMA Psychiatry. 2018;76(1):96-8.

10. De Hert M, Cohen D, Bobes J, Cetkovich-Bakmas M, Leucht S, Ndetei DM, et al. Physical illness in patients with severe mental disorders. II. Barriers to care, monitoring and treatment guidelines, plus recommendations at the system and individual level. World psychiatry. 2011;10(2):138-51.

11. Stahler G, Mennis J, Cotlar R, Baron D. The influence of neighborhood environment on treatment continuity and rehospitalization in dually diagnosed patients discharged from acute inpatient care. American Journal of Psychiatry. 2009;166(11):1258-68.

Page 12/16 
12. Ku BS, Lally CA, Compton MT, Druss BG. Neighborhood predictors of outpatient mental health visits among persons with comorbid medical and serious mental illnesses. Psychiatric Services. 2020:appi.ps.201900363.

13. Kind AJH, Jencks S, Brock J, Yu M, Bartels C, Ehlenbach W, et al. Neighborhood socioeconomic disadvantage and 30-day rehospitalization: A retrospective cohort study. Annals of Internal Medicine. 2014;161(11):765-74.

14. Kirkbride JB, Jones PB, Ullrich S, Coid JW. Social deprivation, inequality, and the neighborhood-level incidence of psychotic syndromes in East London. Schizophrenia Bulletin. 2014;40(1):169-80.

15. Cox M, Boyle PJ, Davey PG, Feng Z, Morris AD. Locality deprivation and Type 2 diabetes incidence: A local test of relative inequalities. Social Science and Medicine. 2007;65(9):1953-64.

16. Almog M, Curtis S, Copeland A, Congdon P. Geographical variation in acute psychiatric admissions within New York City 1990-2000: growing inequalities in service use? Social Science and Medicine. 2004;59(2):361-76.

17. Walsan R, Bonney A, Mayne DJ, Pai N, Feng X, Toms R. Serious mental illness, neighborhood disadvantage, and type 2 diabetes risk: A systematic review of the literature. Journal of Primary Care \& Community Health. 2018;9:2150132718802025.

18. Walsan R, Mayne DJ, Feng X, Pai N, Bonney A. Examining the association between neighbourhood socioeconomic disadvantage and type 2 diabetes comorbidity in serious mental illness. International Journal of Environmental Research and Public Health. 2019;16(20):3905.

19. Durfey SNM, Kind AJH, Buckingham WR, DuGoff EH, Trivedi AN. Neighborhood disadvantage and chronic disease management. Health Services Research. 2019;54:206-16.

20. Jung D, Kind A, Robert S, Buckingham W, DuGoff E. Linking neighborhood context and health in communitydwelling older adults in the Medicare Advantage program. Journal of the American Geriatrics Society. 2018;66(6):1158-64.

21. Hu J, Kind AJH, Nerenz D. Area deprivation index predicts readmission risk at an urban teaching hospital. American Journal of Medical Quality. 2018;33(5):493-501.

22. Baier RR, Gardner RL, Coleman EA, Jencks SF, Mor V, Gravenstein S. Shifting the dialogue from hospital readmissions to unplanned care. American Journal of Managed Care. 2013;19(6):450-3.

23. Feng Z, Wright B, Mor V. Sharp rise in Medicare enrollees being held in hospitals for observation raises concerns about causes and consequences. Health Aff (Millwood). 2012;31(6):1251-9.

24. Healthcare Cost and Utilization Project. SID Database Documentation Rockville, MD2018 [Available from: https://www.hcup-us.ahrq.gov/db/state/siddbdocumentation.jsp.

25. Healthcare Cost and Utilization Project. SEDD Database Documentation Rockville, MD2018 [Available from: https://www.hcup-us.ahrq.gov/db/state/sedddbdocumentation.jsp.

26. University of Wisconsin Department of Medicine School of Medicine and Public Health. Neighborhood Atlas(R) 2020 [Available from: https://www.neighborhoodatlas.medicine.wisc.edu/.

27. Centers for Medicare \& Medicaid Services. 2015 Measure Information About the 30-Day All-Cause Hospital Readmission Measure, Calculated for the Value-Based Payment Modifier Program 2017 [Available from: https://www.cms.gov/Medicare/Medicare-Fee-for-ServicePayment/PhysicianFeedbackProgram/Downloads/2015-ACR-MIF.pdf.

28. Healthcare Cost and Utilization Project. HCUP Supplemental Files for Revisit Analyses Rockville, MD2020 [Available from: www.hcup-us.ahrq.gov/toolssoftware/revisit/revisit.jsp.

29. Ross M, Hockenberry J, Mutter R, Barrett M, Wheatley M, Pitts S. Protocol-driven emergency department observation units offer savings, shorter stays, and reduced admissions. Health Affairs. 2013;32(12):2149-56. 
30. Goldstein JN, Zhang Z, Schwartz JS, Hicks LS. Observation status, poverty, and high financial liability among Medicare beneficiaries. American Journal of Medicine. 2018;131(1):101.e9-.e15.

31. Billings J, Zeitel L, Lukomnik J, Carey TS, Blank AE, Newman L. Impact of socioeconomic status on hospital use in New York City. Health Affairs. 1993;12(1):162-73.

32. Zuckerman RB, Sheingold SH, Orav EJ, Ruhter J, Epstein AM. Readmissions, observation, and the hospital readmissions reduction program. New England Journal of Medicine. 2016;374(16):1543-51.

33. Kripalani S, Theobald CN, Anctil B, Vasilevskis EE. Reducing hospital readmission rates: Current strategies and future directions. Annual Review of Medicine2014. p. 471-85.

34. Nuckols TK, Fingar KR, Barrett ML, Martsolf G, Steiner CA, Stocks C, et al. Returns to emergency department, observation, or inpatient care within 30 days after hospitalization in 4 states, 2009 and 2010 versus 2013 and 2014. Journal of Hospital Medicine. 2018;13(5):296-303.

35. Saver BG, Wang C-Y, Dobie SA, Green PK, Baldwin L-M. The central role of comorbidity in predicting ambulatory care sensitive hospitalizations*. European Journal of Public Health. 2013;24(1):66-72.

\section{Figures}

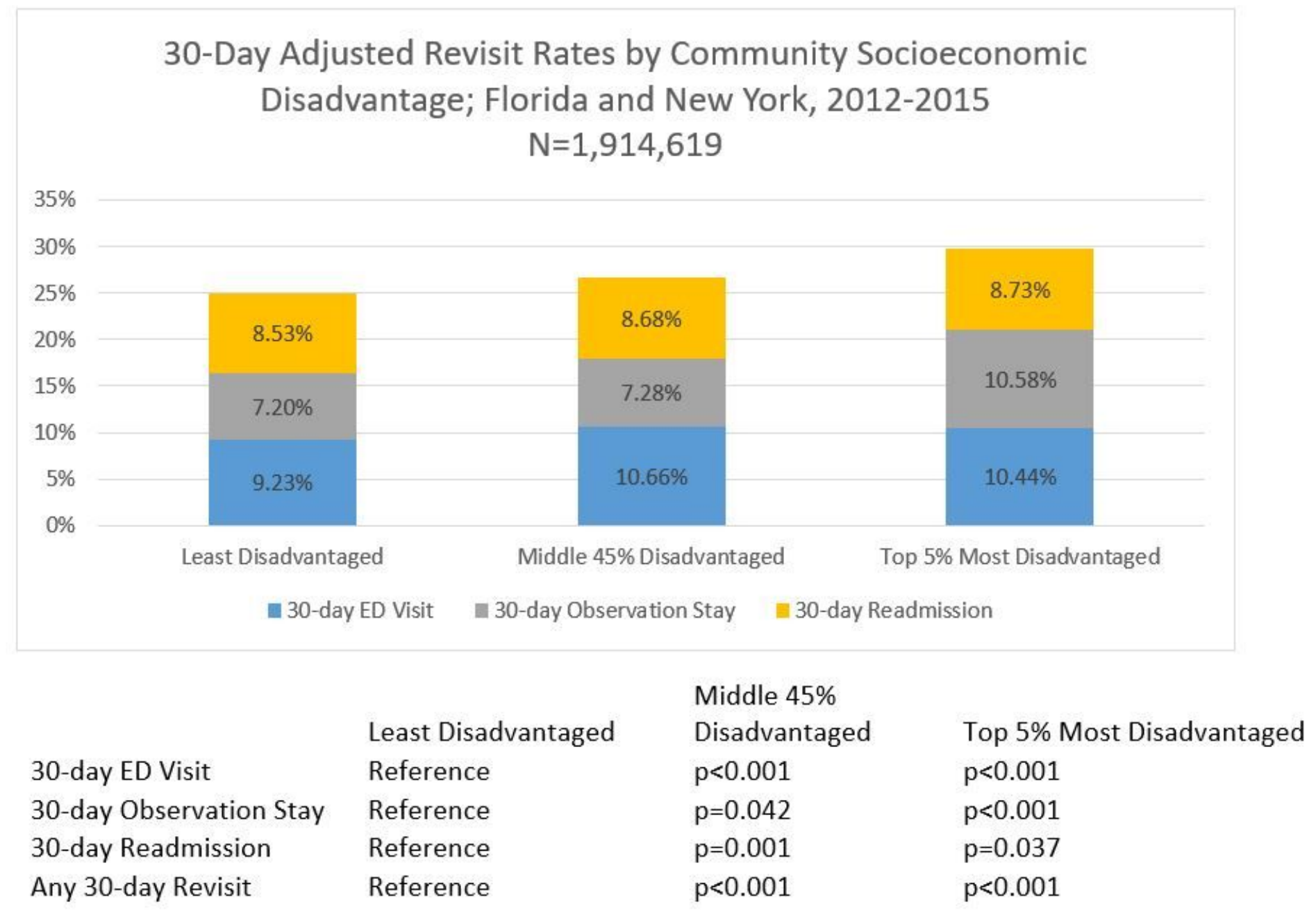

Figure 1 
displays the post-estimation adjusted 30-day revisit rates by community socioeconomic disadvantage (full regression models shown in Supplementary File 3). The adjusted revisit rates were $30.33 \%$ among patients in the most disadvantaged communities, $25.06 \%$ in the middle $45 \%$ of disadvantaged communities, and $25.94 \%$ in the least disadvantaged communities. Adjusted revisit rates based on logistic regressions models with least disadvantaged communities as the reference category after controlling for individual patient-level demographic (i.e. age, sex, primary payer [Medicare, Medicaid, private, self-pay, no charge, or other]) and clinical characteristics (length of stay of the index admission, admission type [emergency, urgent, elective, or trauma center] an indicator for if they had a surgical procedure, Elixhauser comorbidity readmission risk score, and DRG of the index admission) and hospital-level characteristics (teaching status of the hospital [member of Council of Accredited Teaching Hospitals], total number of hospital beds, technology status of the hospital [i.e. capable of performing heart transplant or adult interventional cardiac catheterization], the hospital's nurse-to-bed ratio, and the ownership status of the hospital [i.e. non-federal government, private for profit, or private not-for-profit]); ED = Emergency Department.

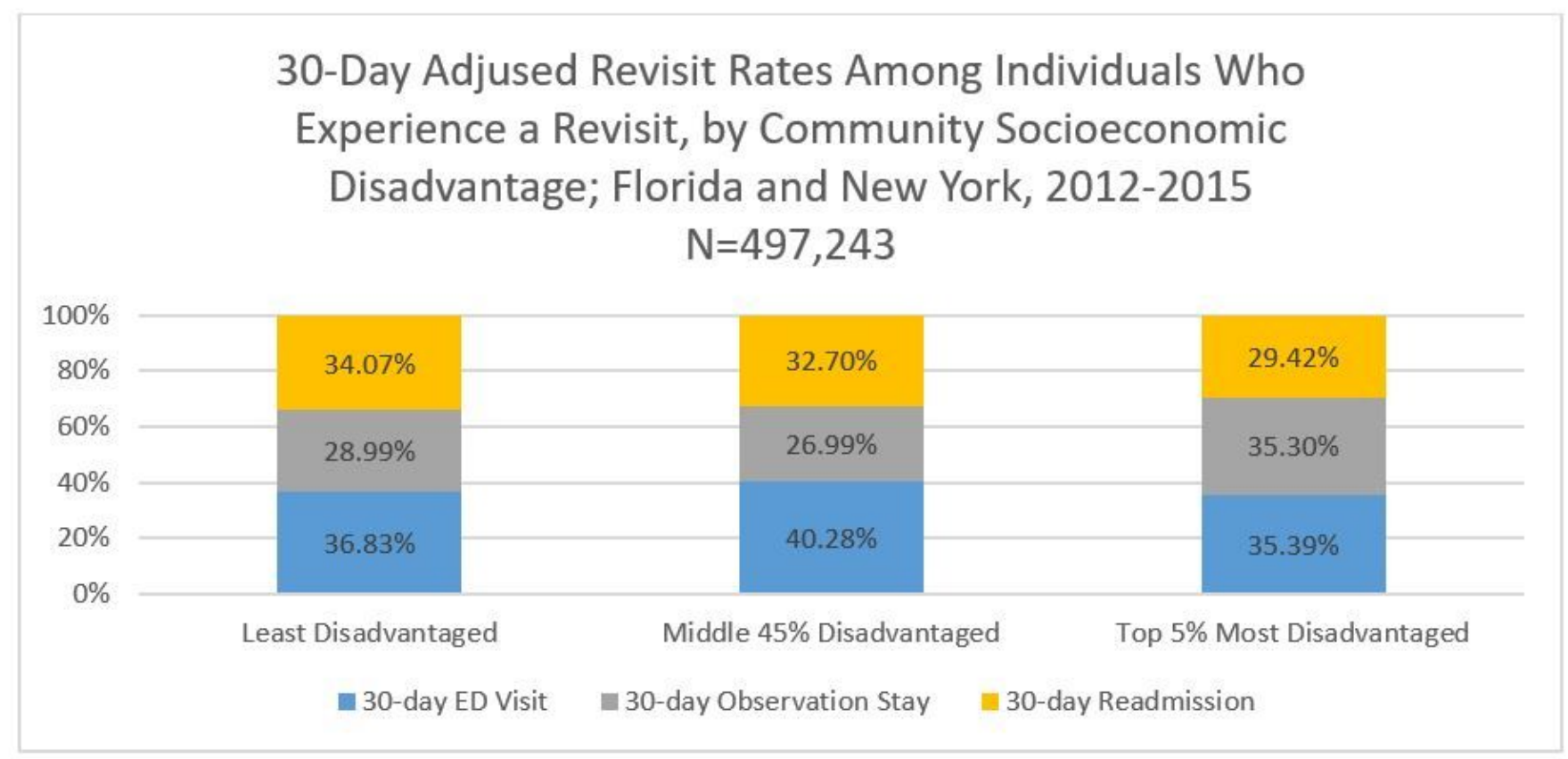

$\begin{array}{llll} & & \text { Middle 45\% } & \\ & \text { Least Disadvantaged } & \text { Disadvantaged } & \text { Top 5\% Most Disadvantaged } \\ \text { 30-day ED Visit } & \text { Reference } & \mathrm{p}<0.001 & \mathrm{p}<0.001 \\ \text { 30-day Observation Stay } & \text { Reference } & \mathrm{p}<0.001 & \mathrm{p}<0.001 \\ \text { 30-day Readmission } & \text { Reference } & \mathrm{p}<0.001 & \mathrm{p}<0.001\end{array}$

\section{Figure 2}

displays the post-estimation adjusted 30-day revisit rates among individuals who experience a revisit, by community socioeconomic disadvantage. The adjusted ED revisit rate was 35.39\% $(p<0.001)$ among the most disadvantaged, $40.28 \%$ ( $p<0.001)$ among the middle $45 \%$, and $36.83 \%$ among the least disadvantaged. The adjusted observation stay revisit rate was $35.30 \%(p<0.001)$ among the most disadvantaged, $26.99 \%(p<0.001)$ among the middle $45 \%$, and $28.99 \%$ among the least disadvantaged. Adjusted revisit rates based on logistic regression models with least disadvantaged communities as the reference category after controlling for individual patient-level demographic (i.e. age, sex, primary payer [Medicare, Medicaid, private, self-pay, no charge, or other]) and clinical characteristics (length of stay of the index admission, admission type [emergency, urgent, elective, or trauma center] an indicator for if they had a surgical procedure, Elixhauser comorbidity readmission risk score, and DRG of the index admission) and 
hospital-level characteristics (teaching status of the hospital [member of Council of Accredited Teaching Hospitals], total number of hospital beds, technology status of the hospital [i.e. capable of performing heart transplant or adult interventional cardiac catheterization], the hospital's nurse-to-bed ratio, and the ownership status of the hospital [i.e. non-federal government, private for profit, or private not-for-profit]); ED = Emergency Department.

\section{Supplementary Files}

This is a list of supplementary files associated with this preprint. Click to download.

- SupplementaryFile3.docx

- SupplementaryFile2.docx

- SupplementaryFile1.docx 